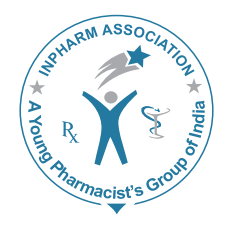

JVP

\title{
Association between Medication Adherence Outcomes and Adverse Drug Reactions to Highly Active Antiretroviral Therapy in Indian Human Immunodeficiency Virus-Positive Patients
}

\author{
Rajesh R, Sudha V'1 Varma DM¹, Sonika S \\ Department of Pharmacy Practice, Manipal College of Pharmaceutical Sciences, Manipal University, Manipal, \\ Karnataka, ${ }^{\prime}$ Department of Medicine, Kasturba Medical College, Manipal University, Manipal, Karnataka, India \\ Address for correspondence: Dr. Radhakrishnan Rajesh, E-mail: rrajesh3775@gmail.com
}

\begin{abstract}
In India, interruptions to highly active antiretroviral therapy (HAART) are due to adverse drug reactions. This study was aimed to assess the association between HAART adherence and adverse drug reactions (ADRs) in human immunodeficiency virus (HIV) patients. This prospective study was conducted at a Medicine department in a South Indian tertiary care teaching hospital. HIV-positive patients were interviewed for adherence using ACTG adherence questionnaire and intensively monitored for ADRs to HAART. The percentage of adherence was calculated based on missed doses, and graded as less than $80 \%, 80-95 \%$, and $>95 \%$. The World Health Organization (WHO) probability scale was used for causality assessment. Logistic regression analysis as well as univariate analysis was used to assess the association ( $P$ value $<0.05)$. A total of 105 HIV-positive patients had been taking HAART out of whom 50 (47.6\%) patients agreed for adherence assessment, and $23(21.9 \%)$ refused due to social stigma. Upon evaluation of the patient characteristics in the reported adherence, $78 \%$ were in males $(53.8 \%)$ and $22 \%$ were in females $(46.2 \%)$ with the level of adherence greater than $95 \%$. Six $(12 \%)$ patients had a regular alcoholic intake with adherence less than $80 \%$ compared to $31(62 \%)$ patients who never had any alcoholic intake $(P<0.05)$. A significant association between ADRs and adherence was found $(P<0.05)$. Causality found by the WHO scale was "probable." Clinicians must focus on education regarding the need for adherence, possible adverse effects, and early detection and prevention of ADRs to HAART.
\end{abstract}

Key words: Adverse drug reaction, highly active antiretroviral therapy, human immunodeficiency virus, medication adherence

\begin{tabular}{|l|l|}
\hline \multicolumn{2}{|c|}{ Access this article online } \\
\hline Quick Response Code: & \\
\hline & Website: \\
\hline & www.jyoungpharm.in \\
& \\
\hline
\end{tabular}

\section{INTRODUCTION}

Human immunodeficiency virus (HIV)-infected patients require a combination of three to four antiretroviral drugs, termed highly active antiretroviral therapy (HAART). Adherence to HAART is increasingly recognized as the key factor to prevent treatment failure in most people with HIV infection. There is a significant association between medication adherence and virological suppression in the treatment of HIV infection..$^{[1,2]}$ India stands at the third position in having the highest burden of HIV/acquired 
immunodeficiency syndrome ${ }^{[3]}$ (AIDS). In India, National AIDS Control Organization (NACO) offers free HAART for HIV and related opportunistic infections. According to NACO guidelines, ${ }^{[3]}$ adherence should be maintained at a minimum of $95 \%$ in order to maintain clinical effectiveness and to minimize the development of drug-resistant strains of HIV. In resource-limited countries like India, failure in HIV treatment is due to drug intolerance or adverse drug reactions (ADRs); unfortunately, $84 \%$ of HIV patients discontinue their initial HAART within the first 8 months of therapy due to ADRs, which leads to non-compliance. ${ }^{[4]}$ In addition, the transmission of drug-resistant viruses is a major health concern. Although many methods have been used in clinical practice to measure adherence, selfreports of the taken medication is the most reasonable, accurate, and ideal to an Indian setup because it promotes a candid exchange between the treating clinician and the treated patient. A number of strategies can be used to improve adherence that include education, simplification of regimen with regard to timing, pill burden and food requirements, avoidance of $\mathrm{ADR}$, and involvement of health care team, family, and friends. The safe and effective management of HIV infection requires understanding of adverse effects associated with HAART because ADRs negatively affect confidence in antiretroviral therapy and medication adherence. HIV-infected patients may stop taking lifelong HAART as a strategy to manage unpleasant symptoms or to avoid adverse health outcomes associated with HAART. Hence, adherence may be compromised, leading to treatment failure, increased hospitalization, and to morbidity and mortality, which significantly affects the quality of life. To date, no study has been published from India on the effects of adverse drug reaction on medication adherence and its outcome in HIV-infected patients. The study was aimed to assess the association between self-reported HAART adherence outcomes and ADRs in Indian HIV-positive patients.

\section{MATERIALS AND METHODS}

This was a prospective study conducted from October 2010 to June 2011 among HIV-infected patients by a clinical pharmacist at a Medicine department in a teaching hospital where ADR reporting exists. The study was approved by the institutional ethics committee. HIV- infected hospitalized patients of either sex who were on HAART were included in the study; HIV-positive patients who refused for medication adherence interview, patients with traditional medicines alone, and pregnant women were excluded from medication adherence assessment. Based on the study criteria, the study procedure was explained and informed consent was taken from the patients. The AIDS Clinical Trail Group (ACTG) adherence questionnaire ${ }^{[5]}$ was used for medication adherence assessment. Demographic details, information on sociodemographic factors, psychological factors, disclosure of status, social habits, time of diagnosis of HIV, health care system and health care professional-related factors, HAART-related factors, knowledge and belief related to HAART, and reasons for lack of adherence ${ }^{[6]}$ were documented in adherence assessment. Agreed patients for adherence assessment were interviewed and asked to recall and report the number of missed antiretroviral doses in the last one month (each missed medication regarded as one dose). The percentage of adherence from self-report was calculated by using the following formula: ${ }^{[7]}$

$$
\begin{aligned}
& \text { Percentage of } \\
& \text { adherence }
\end{aligned}=\frac{\begin{array}{c}
\text { No. of doses the patient should } \\
\text { have taken }- \text { No. of doses missed }
\end{array}}{\begin{array}{c}
\text { No. of doses the patient } \\
\text { should have taken }
\end{array}} \times 100
$$

The level of adherence was graded as less than $80 \%, 80 \%$ $95 \%$, and greater than $95 \%$ as per NACO guidelines. ${ }^{[3]}$ As HAART is a life-long therapy in an HIV- infected patient, it is more meaningful to evaluate long-term and short-term ADRs associated with HAART; hence, during the study period, adherence interview for HIV-infected, hospitalized in-patients was intensively monitored for ADRs by active follow-up after treatment, and adverse events were detected by asking patients directly or screening patient records in order to correlate medication adherence and ADRs to HAART. Treatment charts and patient case notes were made; CD4 count, HAART status, occurrence of ADRs, HAART regimen implicated in ADRs, duration of therapy, route of administration, dosage, with frequency, complementary treatment, patient's allergic status to food and drugs, and use of oral contraceptives were also documented. Naranjo's algorithm ${ }^{[8]}$ and World Health Organization's ADR probability scale ${ }^{[9]}$ were used for the causality assessment of ADRs. If there was a history of allergy or reactions to the medication during previous exposure, the ADR was considered "predictable." Modified Shumock and Thornton criteria ${ }^{[10]}$ were used to assess the preventability of ADRs. The severity of suspected ADRs was assessed using the modified Hart wig and Siegel scale. ${ }^{[1]}$ The ADR was considered as "not predictable" if the drug had previously been well tolerated by the patient at the same dose and route of administration. WHO adverse reaction terminologies (WHO-ART) for system organ class $\operatorname{codes}^{[12]}$ were used to code the suspected ADR. ADR with a literature 
incidence of $\geq 1 / 100$ was considered "predictable." Any suspected ADR documented with HAART was reviewed and assessed by a senior academic clinical pharmacist and was reported to the treating clinicians.

\section{Statistical analysis}

Logistic regression analysis as well as univariate analysis was used to find an association between self-reported medication adherence and ADRs. A classification and regression tree was used to establish continuous variable cut points. All statistical calculations were performed using Statistical Package for Social Science (SPSS), version 17.0. A $P$-value of $<0.05$ was considered as statistically significant.

\section{RESULTS}

During the study period, a total of 105 HIV positive patients were taking HAART. Of these, $50(47.6 \%)$ patients agreed to participate and agreed to be interviewed, 23 $(21.9 \%)$ refused for adherence assessment interview, and $32(30.5 \%)$ did not meet the inclusion criteria. Majority of the patients were males, 68 (64.8\%), compared to females, $37(35.2 \%)$. Majority of patients were greater than 48 years of age $(44.8 \%)$. Most of the patients were unemployed $(68,64.8 \%)$ and married $(86,81.9 \%)$. Over $62.9 \%$ of the patients were HAART experienced, $29.5 \%$ of the patients were HAART new, i.e., naïve, and $7.6 \%$ of the study patients were HAART defaulters. Patients' demographic details are shown in Table 1.

Out of 50 patients for adherence assessment interview, $78 \%$ were males with a $53.8 \%$ level of adherence, greater than $95 \%$, compared to females $(22 \%)$ with a $46.2 \%$ adherence level. A level of adherence greater than 95\% was seen in the age group of $39-48$ years $(6,46.2 \%)$ and married patients $(11,84.6 \%)$. Most of the patients were unemployed $(29,58 \%)$ with secondary school education (37, 74\%); employed patients had an average monthly income of INR 5000-10,000 (US\$96.15-192.30). Among the psychological factors for adherence assessment in our study, results showed that patients reported that they had disclosed their HIV status to the spouse $(33,66 \%$; $P=0.040$, i.e., $P<0.05)$ and $43(86 \%)$ of the patients reported that they had received help from family members in taking their medication regularly $(P=0.049$, i.e., $P<0.05)$. A total of $40(80 \%)$ patients felt that support from family was needed strongly in order to have good adherence. Table 2 depicts the details of socio-demographic and psychological factors for adherence.

A total of $49(98 \%)$ patients reported that they were aware about the significance of HAART therapy and 15 (30\%) patients were following all instructions regularly provided by the treating clinician. A total of $8(16 \%)$ patients reported that they had never followed instructions and left the treatment in between due to various reasons such as feeling better, financial problem, alcohol intake, or busy schedule. Following the instructions as per the treating clinician was found to be statistically significant $(P=0.001$, i.e., $P<0.05)$. The reason for difficult followup of HAART was due to cost $(25,50 \%)$ followed by financial discomfort $(14,28 \%)$. We found that $6(12 \%)$ patients with regular alcoholic intake had poor adherence (less than 80\%) compared to $31(62 \%)$ patients who never

Table 1: Demographic characteristic of patients on highly active antiretroviral therapy

\begin{tabular}{|c|c|}
\hline Characteristic & $\begin{array}{l}\text { Total number of patients on HAART } \\
\qquad n=105(\%)\end{array}$ \\
\hline \multicolumn{2}{|l|}{ Gender } \\
\hline Male & $68(64.8)$ \\
\hline Female & $37(35.2)$ \\
\hline \multicolumn{2}{|l|}{ Age group (years) } \\
\hline $18-28$ & $8(7.6)$ \\
\hline $29-38$ & $23(21.9)$ \\
\hline $39-48$ & $47(44.8)$ \\
\hline $49-58$ & $19(18.1)$ \\
\hline $59-68$ & $8(7.6)$ \\
\hline \multicolumn{2}{|l|}{$\operatorname{BMI}\left(\mathrm{kg} / \mathrm{m}^{2}\right)$} \\
\hline 18.4 & $37(35.2)$ \\
\hline $18.5-24.5$ & $53(50.4)$ \\
\hline$\geq 25$ & $6(5.8)$ \\
\hline$\geq 30$ & $9(8.6)$ \\
\hline \multicolumn{2}{|l|}{ Marital status } \\
\hline Single & $6(5.7)$ \\
\hline Married & $86(81.9)$ \\
\hline Widowed & $8(7.6)$ \\
\hline Separated & $5(4.8)$ \\
\hline \multicolumn{2}{|l|}{ Occupation } \\
\hline Employed & $37(35.2)$ \\
\hline Unemployed & $68(64.8)$ \\
\hline \multicolumn{2}{|l|}{ Alcoholic } \\
\hline Yes & $31(29.5)$ \\
\hline No & $74(70.5)$ \\
\hline \multicolumn{2}{|l|}{ Smoker } \\
\hline Yes & $27(25.7)$ \\
\hline No & $78(74.3)$ \\
\hline \multicolumn{2}{|l|}{ Complementary treatment } \\
\hline Yes & $9(8.6)$ \\
\hline No & $96(91.4)$ \\
\hline \multicolumn{2}{|l|}{ Status of HAART } \\
\hline HAART naïve & $31(29.5)$ \\
\hline HAART experienced & $66(62.9)$ \\
\hline HAART defaulter & $8(7.6)$ \\
\hline \multicolumn{2}{|l|}{ Adherence assessment status } \\
\hline Interviewed and assessed & $50(47.6)$ \\
\hline Refused to be Interviewed & $23(21.9)$ \\
\hline Non-eligible & $32(30.5)$ \\
\hline
\end{tabular}

HAART $=$ highly active antiretroviral therapy 
Table 2: Sociodemographic and psychological factors for adherence

\begin{tabular}{|c|c|c|c|c|c|}
\hline \multirow{3}{*}{$\begin{array}{l}\text { Sociodemographic factors for } \\
\text { adherence }\end{array}$} & \multirow[t]{3}{*}{$n=50(\%)$} & \multicolumn{3}{|c|}{ Percentage of adherence } & \multirow[t]{3}{*}{$P$-value } \\
\hline & & $<\mathbf{8 0 \%}$ & $80-95 \%$ & $>95 \%$ & \\
\hline & & $n=23$ & $n=14$ & $n=13$ & \\
\hline \multicolumn{6}{|l|}{ Gender } \\
\hline Male & $39(78)$ & $20(87)$ & $12(85.7)$ & $7(53.8)$ & 0.05 \\
\hline Female & $11(22)$ & $3(13)$ & $2(14.3)$ & $6(46.2)$ & \\
\hline \multicolumn{6}{|l|}{ Age group (years) } \\
\hline $18-28$ & $3(6)$ & $1(4.3)$ & $1(7.1)$ & $1(7.7)$ & 0.147 \\
\hline $29-38$ & $13(26)$ & $7(30.5)$ & $2(14.3)$ & $4(30.8)$ & \\
\hline $39-48$ & $23(46)$ & $12(52.2)$ & $5(35.7)$ & $6(46.2)$ & \\
\hline $49-58$ & $10(20)$ & $2(8.7)$ & $6(42.9)$ & $2(15.3)$ & \\
\hline $59-68$ & $1(2)$ & $1(4.3)$ & & & \\
\hline \multicolumn{6}{|l|}{ Marital status } \\
\hline Single & $4(8)$ & $2(8.7)$ & $1(7.1)$ & $1(7.7)$ & 0.048 \\
\hline Married & $37(74)$ & $16(69.6)$ & $10(71.5)$ & $11(84.6)$ & \\
\hline Widowed & $4(8)$ & $2(8.7)$ & $1(7.1)$ & $1(7.7)$ & \\
\hline Separated/divorced & $5(10)$ & $3(13)$ & $2(14.3)$ & & \\
\hline \multicolumn{6}{|l|}{ Level of education } \\
\hline Primary school & $4(8)$ & $2(8.7)$ & $1(7.1)$ & $1(7.7)$ & 0.362 \\
\hline Secondary school & $37(74)$ & $18(78.3)$ & $8(57.1)$ & $11(84.6)$ & \\
\hline College level Illiterate & $9(18)$ & $3(13)$ & $5(35.7)$ & $1(7.7)$ & \\
\hline \multicolumn{6}{|l|}{ Occupation } \\
\hline Employed & $21(42)$ & $12(52.2)$ & $6(42.9)$ & $3(23.1)$ & 0.235 \\
\hline Unemployed & $29(58)$ & $11(47.8)$ & $8(57.1)$ & $10(76.9)$ & \\
\hline \multicolumn{6}{|l|}{ Income in per month (INR) } \\
\hline$<5000^{\mathrm{a}}$ & $13(26)$ & $6(26.1)$ & $3(21.4)$ & $4(30.8)$ & 0.180 \\
\hline $5000-10,000^{b}$ & $19(38)$ & $9(39.1)$ & $4(28.6)$ & $6(46.2)$ & \\
\hline $10,000-20,000^{\mathrm{c}}$ & $15(30)$ & $8(34.8)$ & $4(28.6)$ & $3(23.0)$ & \\
\hline$>200,000^{\mathrm{d}}$ & $3(6)$ & & $3(21.4)$ & & \\
\hline \multicolumn{6}{|c|}{ Psychological factors for adherence } \\
\hline \multicolumn{6}{|l|}{ Disclosed to spouse } \\
\hline Yes & $33(66)$ & $8(34.8)$ & $13(92.8)$ & $12(92.3)$ & 0.040 \\
\hline No & $17(34)$ & $15(65.2)$ & $1(7.2)$ & $1(7.7)$ & \\
\hline \multicolumn{6}{|l|}{$\begin{array}{l}\text { Help from family members in } \\
\text { taking medicines regularly }\end{array}$} \\
\hline Yes & $43(86)$ & $21(91.3)$ & $12(85.7)$ & $10(76.9)$ & 0.049 \\
\hline No & $7(14)$ & $2(8.7)$ & $2(14.3)$ & $3(23.1)$ & \\
\hline \multicolumn{6}{|l|}{ Moral support from family } \\
\hline Yes & $40(80)$ & $17(74)$ & $11(78.5)$ & $12(92.3)$ & 0.032 \\
\hline No & $10(20)$ & $6(26)$ & $3(21.5)$ & $1(7.7)$ & \\
\hline
\end{tabular}

had alcoholic habits which resulted in good adherence (greater than $95 \% ; P=0.027$, i.e., $P<0.05$ ). The overall adherences to HAART in case of smokers $(10,20 \%)$ and nonsmokers $(33,66 \%)$ were poor (less than $80 \%$ ). In our study, none of them reported the use of IV drugs. Table 3 summarizes health care and social factors for adherence.

Majority of the patients $(29,58 \%)$ were able to identify their ART medication by brand name and were on HAART for more than a year. Most (45, 90\%) of the patients knew that HAART had been prescribed to them to slow down the progression of HIV; 30 (60\%) patients found the HAART treatment difficult to afford. A total of $31(62 \%)$ of patients showed the behavior of skipping medication regularly which resulted in poor adherence (less than 80\%). Regarding the knowledge and beliefs related to HAART, our results were found to be statistically significant $(P<0.05)$ for timings of medication; 33 (66\%) believed that antiretroviral treatment should be taken on time as prescribed by the clinician, $34(68 \%)$ felt that special instructions given along with HAART are important to be followed, 29 (58\%) felt that the treatment should not stopped and should be continued, and $44(88 \%)$ patients agreed that HAART is life saving. Fisher's exact test revealed that the occurrence of ADRs to antiretroviral therapy was significantly associated and significantly predicted with the percentage of adherence 
Table 3: Health care and social factors for adherence

\begin{tabular}{|c|c|c|c|c|c|}
\hline \multirow{3}{*}{$\begin{array}{l}\text { Health care- system and health care } \\
\text { team-related factors }\end{array}$} & \multirow{3}{*}{$\begin{array}{l}\text { Number of patients } n \\
=\mathbf{5 0}(\%)\end{array}$} & \multicolumn{3}{|c|}{ Percentage of adherence } & \multirow[t]{3}{*}{$P$-valu } \\
\hline & & $<80 \%$ & $80-95 \%$ & $>95 \%$ & \\
\hline & & $n=\mathbf{2 3}$ & $n=14$ & $n=13$ & \\
\hline \multicolumn{6}{|c|}{ Knowledge about importance of taking medicines needed? } \\
\hline Yes & $49(98)$ & $22(95.7)$ & $14(100)$ & $13(100)$ & 0.549 \\
\hline No & $1(2)$ & $1(4.3)$ & & & \\
\hline \multicolumn{6}{|l|}{$\begin{array}{l}\text { How often do you follow instructions } \\
\text { provided by the clinician? }\end{array}$} \\
\hline Never & $8(16)$ & $8(34.8)$ & & & 0.001 \\
\hline Sometime & $12(24)$ & $11(47.8)$ & $1(7.1)$ & & \\
\hline Most of the time & $15(30)$ & $4(17.4)$ & $8(57.1)$ & $3(23.1)$ & \\
\hline All the time & $15(30)$ & 0 & $5(35.8)$ & $10(76.9)$ & \\
\hline \multicolumn{6}{|l|}{ Difficulty in follow-up } \\
\hline Yes & $30(60)$ & $16(69.6)$ & $7(50)$ & $7(53.8)$ & 0.435 \\
\hline No & $20(40)$ & $7(30.4)$ & $7(50)$ & $6(46.2)$ & \\
\hline \multicolumn{6}{|l|}{ Reason for difficult follow-up } \\
\hline \multicolumn{6}{|l|}{ Cost } \\
\hline Yes & $25(50)$ & $13(56.5)$ & $6(42.9)$ & $6(46.2)$ & 0.686 \\
\hline No & $25(50)$ & $10(43.5)$ & $8(57.1)$ & $7(53.8)$ & \\
\hline \multicolumn{6}{|l|}{ Discomfort } \\
\hline Yes & $14(28)$ & $7(30.4)$ & $4(28.6)$ & $3(23.1)$ & 0.893 \\
\hline No & $36(72)$ & $16(69.6)$ & $10(71.4)$ & $10(76.9)$ & \\
\hline \multicolumn{6}{|l|}{ Lack of time } \\
\hline Yes & $7(14)$ & $3(13)$ & $3(21.4)$ & $1(7.7)$ & 0.580 \\
\hline No & $43(86)$ & $20(87)$ & $11(78.6)$ & $12(92.3)$ & \\
\hline \multicolumn{6}{|l|}{ Distance to center } \\
\hline Yes & $2(4)$ & $1(4.3)$ & $1(7.1)$ & $13(100)$ & 0.635 \\
\hline No & $48(96)$ & $22(95.7)$ & $13(92.9)$ & & \\
\hline \multicolumn{6}{|l|}{ Social factors for adherence } \\
\hline \multicolumn{6}{|l|}{ Alcohol } \\
\hline Regular & $6(12)$ & $5(21.7)$ & $1(7.1)$ & $1(7.7)$ & 0.027 \\
\hline Occasional & $4(8)$ & $3(13.1)$ & $4(28.6)$ & $1(7.7)$ & \\
\hline Rare & $1(2)$ & $1(4.3)$ & $9(64.3)$ & $11(84.6)$ & \\
\hline Reformed & $8(16)$ & $3(13.1)$ & & & \\
\hline Never & $31(62)$ & $11(47.8)$ & & & \\
\hline \multicolumn{6}{|l|}{ Smoking } \\
\hline Regular & $10(20)$ & $7(30.5)$ & $2(14.3)$ & $1(7.7)$ & 0.391 \\
\hline Occasional & $1(2)$ & $1(4.3)$ & $3(21.4)$ & $1(7.7)$ & \\
\hline Rare & $1(2)$ & $1(4.3)$ & $9(64.3)$ & $11(84.6)$ & \\
\hline Reformed & $5(10)$ & $1(4.3)$ & & & \\
\hline Never & $33(66)$ & $13(56.6)$ & & & \\
\hline
\end{tabular}

A $P$-value of $<0.05$ was considered as statistically significant

being less than $80 \%(P<0.001)$. Table 4 highlights the HAART-related factors, knowledge, beliefs related to ART, and ADRs reported.

Out of $50 \mathrm{HIV}$-infected patients for adherence assessment, patients with ADRs were 32 (27 males, 84.4\%, and 5 females, $15.6 \%)$ in number. The majority of patients with ADR were in the age group of 39-48 years. Most of the patients with ADRs were agriculturists (37.5\%). Four patients $(12.5 \%)$ were on both HAART and complementary treatment. The majority $(93.7 \%)$ of patients with ADRs were HAART experienced. The CD4 count in the majority of patients $(78.1 \%)$ with ADRs was $\leq 200$ cells $/ \mu$ l. In the majority of ADRs, occurrence was reported at the time of hospital admission (37.6\%) followed by previous exposure to ADRs, and during hospital stay (31.2\%). During the study, 37.5\% ADRs to HAART were observed due to polypharmacy (four to five drugs). A higher rate of ADRs was noted with the zidovudine + lamivudine + nevirapine combination $(31.5 \%)$, while the lowest rate of ADRs was noted with atazanavir + ritonavir + tenofovir + emtricitabine (3.1\%). Table 5 represents the demographic details of the patients with ADRs.

The WHO probability scale was "probable" (50\%) and "possible" (31.2\%) and by Naranjo's algorithm, causality was "probable" (68.8\%) and "possible" (25\%). Most of the ADRs that were "moderate" in severity on Hart -wig et al.'s scale 
Table 4: Highly active antiretroviral therapy-related factors, knowledge, and beliefs related to ART and ADRs

\section{reported}

Highly active antiretroviral therapy-related factors $\quad$ Number of patients $n=50(\%)$

ART identification
By brand name
By medication wrapper
By color, shape, size
Cannot identify

Frequency

Once/day

Twice/day

No. of pills/day

One

Two

Three

Duration of ART

6 months

More than a year

Reason of taking ART

To prevent progression of HIV

To increase CD4 count

Both

Don't know

Attitude of treatment to ART

Very well

Okay

Not well

Frequency of skipping medication

Yes, very often

Sometimes

No

Behavior of skipping

Skip regularly

Take when remember

Skip if it's time for the next dose

Double the dose

ART affordable?

Yes

No

Knowledge and belief related to ART

Medications to be taken for whole life?

Yes

No

Don't know

Time of medication will affect the effectiveness of

treatment?

Yes

No

Don't know

Do you think special instructions are necessary to be

followed?

Yes

No

Don't know

Once after getting better Can you stop drugs?

Yes

No
$29(58)$

$16(32)$

2 (4)

$3(6)$

$15(30)$

$35(70)$

12 (24)

22 (44)

16 (32)

21 (42)

29 (58)

45 (90)

1 (2)

3 (6)

1 (2)

13 (26)

18 (36)

19 (38)

17 (34)

18 (36)

$15(30)$

31 (62)

3 (6)

1 (2)

15 (30)

$30(60)$

20 (40)

49 (98)

1 (2)

33 (66)

3 (6)

14 (28)

34 (68)

3 (6)

13 (26)

29 (58)

6 (12)

\begin{tabular}{ccc}
\multicolumn{3}{c}{ Percentage of adherence } \\
\hline$<80 \%$ & $\mathbf{8 0 - 9 5 \%}$ & $>95 \%$ \\
\hline$n=23$ & $n=14$ & $n=13$
\end{tabular}

$13(56.5)$

$7(30.4)$

$10(71.4)$

3 (21.5)

6 (46.2)

$6(46.2)$

$-$

3 (13)

7 (30.4)

$16(69.6)$

$1(7.1)$

$13(92.9)$

$6(26.1)$

$11(47.8)$

$1(7.1)$

$5(35.7)$

$6(26.1)$

$8(57.2)$

7 (30.4)

5 (35.7)

$16(69.6)$

$9(64.3)$

$21(91.4)$

$1(4.3)$

$-$

$1(4.3)$

5 (21.7)

8 (34.8)

$10(43.5)$

14 (100)

$-$

- $\quad 3(23.1)$

$-$

2 (14.2)

6 (42.9)

6 (46.2)

4 (30.8)

$6(42.9) \quad 3(23.0)$

16

7

$$
-
$$

$21(91.3)$

2 (8.7)

$$
-
$$

$13(56.5)$

$10(43.5)$

$22(95.7)$

$14(100)$

$13(100)$

0.549

$1(4.3)$

8 (34.8)

3 (13)

12 (52.2)

12 (85.7)

$-$

2 (14.3)

9 (39.1)

$12(85.7)$

3 (13)

11 (47.8)

-

$5(21.7)$

4 (17.4)

$P$-value

0.293

0.147

6 (46.1)

2 (15.4)

9 (69.2)

0.06

0.080

0.487

2

11

$1(7.7)$

0.487

$1(7.7)$

$11(84.6)$

7 (53.8)

6 (46.2)

0.582

4 (28.6) $6(46.2)$

$11(78.6)$

13 (100)

0.001 
Rajesh, et al:: Medication adherence outcomes and adverse drug reactions

Table 4: Contd...

\begin{tabular}{|c|c|c|c|c|c|}
\hline \multirow[t]{3}{*}{ Highly active antiretroviral therapy-related factors } & \multirow[t]{3}{*}{ Number of patients $n=\mathbf{5 0}(\%)$} & \multicolumn{3}{|c|}{ Percentage of adherence } & \multirow[t]{3}{*}{$P$-value } \\
\hline & & $<\mathbf{8 0} \%$ & $80-95 \%$ & $>95 \%$ & \\
\hline & & $n=23$ & $n=14$ & $n=13$ & \\
\hline Don’t know & $15(30)$ & $14(60.9)$ & $1(7.1)$ & - & \\
\hline \multicolumn{6}{|l|}{ Do you know ART is life saving? } \\
\hline Yes & $44(88)$ & $17(73.9)$ & $14(100)$ & $13(100)$ & 0.091 \\
\hline No & $1(2)$ & $1(4.3)$ & - & - & \\
\hline Don't know & $5(10)$ & $5(21.7)$ & - & - & \\
\hline \multicolumn{6}{|l|}{ Adverse drug reactions } \\
\hline Present & $32(64)$ & $13(56.5)$ & $12(85.7)$ & $7(53.8)$ & $<0.001$ \\
\hline Absent & $18(36)$ & $10(43.5)$ & $2(14.3)$ & $6(46.2)$ & \\
\hline
\end{tabular}

ART $=$ Antireroviral therapy; A $P$-value of $<0.05$ was considered as statistically significant

(71.8\%) were required discontinuation of suspected drug (s). Of the 32 ADRs, 69 (87.5\%) were "predictable" and $4(12.5 \%)$ were "non-predictable." The majority of ADRs (53.1\%) were "non-preventable," 18.1\% "probably preventable," and $28.1 \%$ were "definitely preventable," as found by the modified Schumock and Thornton scale. The suspected drug was withdrawn in $62.5 \%$ of patients with ADRs.

Symptomatic treatment was instituted in $34.3 \%$ of the ADR cases. Most $(78.1 \%)$ of the patients were recovered while $15.7 \%$ had ADRs till the day of discharge. A total of $6.2 \%$ of patients with ADRs were discharged from the hospital against medical advice, resulting in an unknown outcome of ADRs. The ADR reported was zidovudin-induced anemia (22\%), zidovudin-induced pancytopenia (18.9\%), and tenofovir-induced renal failure $(12.6 \%)$. The organ system affected was red blood cell disorders (43.8\%) followed by urinary system disorders $(12.5 \%)$ as per system organ class codes. Table 6 represents the causality assessment of ADRs. The reasons for the lack of adherence to antiretroviral therapy in our study include ADR/toxicity/side-effects (64\%); forgetting to take medication (44\%); being too ill (46\%); social stigma, disclosure, and privacy issues $(14 \%)$; drug stock out ( $8 \%$ ); patient losing/running out of pill $(10 \%)$; delivery/travel problems (4\%); inability to pay for HAART (70\%); depression (8\%); and alcohol usage (4\%).

\section{DISCUSSION}

This is the first study conducted on Indian HIV-infected patients that explores the association of medication adherence outcomes based on self-report and the occurrence of ADRs to HAART. We found that most $(26 \%)$ of our patients had good adherence to HAART (greater than 95\%) because most of them were married $(P=0.048$, i.e. $P<0.05)$, as marriage favors the disclosure of HIV-positive status to the spouse $(P=0.040$, i.e. $P<0.05)$ and the spouse acts as a great source of social support (reminding about pill taking, etc.). Our results were comparatively low with other studies Amberbir et al. ${ }^{[13]}$ and Gifford et al. ${ }^{[14]}$ Interestingly, in our study, $21.9 \%$ of HIVinfected patients refused for interview for adherence assessment due to social stigma and illiteracy.

Most of our patients were well educated, but unable to express their symptoms of adverse drug effects to clinicians due to fear and their personal beliefs regarding intentional non-adherence. This finding is consistent with various studies. ${ }^{[15-17]}$ Most of our patients were nonalcoholics $(P=0.027$, i.e. $P<0.05)$ and non-smokers $(P=0.039$, i.e. $P<0.05)$, the traits being positively associated with adherence to antiretroviral therapy. This finding is consistent with various study reports. ${ }^{[18,19]}$ In our study, factors such as unemployment and low income (less than INR 5000; less than US\$96.15) were negatively associated with adherence. This might be due to the fact that most of our patients were below the poverty line, even unable to afford their daily food and inability to pay for antiretroviral therapy. This is in accordance with published studies. ${ }^{[20]}$

Our study shows that HIV disclosure to spouse $(P=0.04$, i.e., $P<0.05)$ was significantly and positively correlated with getting help in taking medicines regularly from family and gaining overall moral support $(P=0.03$, i.e., $P<0.05)$ from them in order to have good adherence, and significantly indicates that HIV disclosure avoids depressive illness and also psychological stress associated with HIV infection. Similar results have been reported from various studies. ${ }^{[21-23]}$

Patients' knowledge and belief related to antiretroviral therapy in our study was statistically significant $(P<0.05)$ for good adherence with a higher self-efficacy belief, i.e., confidence about one's ability to maintain a behavior regarding their antiretroviral medications. This finding was in accordance with another study ${ }^{[14]}$ where it was reported that patients with self-efficacy beliefs were found to have 
Table 5: Demographic details of the patients with adverse drug reactions

\begin{tabular}{|c|c|}
\hline Characteristic & $\begin{array}{c}\text { Total number of patients with adverse } \\
\text { drug reactions } N=32(\%)\end{array}$ \\
\hline \multicolumn{2}{|l|}{ Gender } \\
\hline Male & $27(84.4)$ \\
\hline Female & $5(15.6)$ \\
\hline \multicolumn{2}{|l|}{ Age group (years) } \\
\hline $18-28$ & $2(6.3)$ \\
\hline $29-38$ & $8(25)$ \\
\hline $39-48$ & $13(40.6)$ \\
\hline $49-58$ & $9(28.1)$ \\
\hline \multicolumn{2}{|l|}{ BMI $\left(\mathrm{kg} / \mathrm{m}^{2}\right)$} \\
\hline 18.4 & $13(40.7)$ \\
\hline $18.5-24.5$ & $17(53.1)$ \\
\hline$\geq 25$ & $1(3.1)$ \\
\hline$\geq 30$ & $1(3.1)$ \\
\hline \multicolumn{2}{|l|}{ Marital status } \\
\hline Single & $3(9.3)$ \\
\hline Married & $23(71.9)$ \\
\hline Widowed & $2(6.2)$ \\
\hline Separated & $4(12.6)$ \\
\hline \multicolumn{2}{|l|}{ Occupation } \\
\hline Housewife & $4(12.5)$ \\
\hline Agriculturist & $12(37.5)$ \\
\hline Employed & $11(34.4)$ \\
\hline Selfemployed & $4(12.5)$ \\
\hline Student & $1(3.1)$ \\
\hline \multicolumn{2}{|l|}{ Alcoholic } \\
\hline Regular & $4(12.5)$ \\
\hline Occasional & $3(9.4)$ \\
\hline Rare & $1(3.1)$ \\
\hline Reformed & $7(21.9)$ \\
\hline Never & $17(53.1)$ \\
\hline \multicolumn{2}{|l|}{ Smoker } \\
\hline Regular & $8(25)$ \\
\hline Occasional & -- \\
\hline Rare & $1(3.1)$ \\
\hline Reformed & $5(15.6)$ \\
\hline Never & $18(56.3)$ \\
\hline \multicolumn{2}{|l|}{ Complementary treatment } \\
\hline Yes & $4(12.5)$ \\
\hline No & $28(87.5)$ \\
\hline \multicolumn{2}{|l|}{ HAART status } \\
\hline HAART experienced & $30(93.7)$ \\
\hline HAART defaulter & $2(6.3)$ \\
\hline \multicolumn{2}{|l|}{ CD4 count (cells/ $\mu \mathrm{l})$} \\
\hline$\leq 200$ & $25(78.1)$ \\
\hline$>200$ & 7 (21.9) \\
\hline \multicolumn{2}{|l|}{ Occurrence of ADRs } \\
\hline ADRs during hospital stay & $10(31.2)$ \\
\hline ADRs at the time of admission & $12(37.6)$ \\
\hline Previous exposure of ADRs & $10(31.2)$ \\
\hline \multicolumn{2}{|l|}{ Polypharmacy } \\
\hline Minor (two to three drugs) & $4(12.5)$ \\
\hline Moderate (four to five drugs) & $12(37.5)$ \\
\hline Major (greater than five drugs) & $16(50)$ \\
\hline $\begin{array}{l}\text { Highly active antiretroviral } \\
\text { therapy implicated in ADRs }\end{array}$ & \\
\hline
\end{tabular}

Contd....
Table 5: Contd...

\begin{tabular}{|c|c|}
\hline Characteristic & $\begin{array}{c}\text { Total number of patients with adverse } \\
\text { drug reactions } N=32(\%)\end{array}$ \\
\hline $\begin{array}{l}\text { Zidovudine }+ \text { lamivudine }+ \\
\text { nevirapine }\end{array}$ & $10(31.5)$ \\
\hline $\begin{array}{l}\text { Zidovudine + lamivudine }+ \\
\text { efavirenz }\end{array}$ & $7(22)$ \\
\hline $\begin{array}{l}\text { Tenofovir + lamivudine }+ \\
\text { efavirenz }\end{array}$ & $2(6.2)$ \\
\hline $\begin{array}{l}\text { Tenofovir + efavirenz } \\
+ \text { +emtricitabine }\end{array}$ & $2(6.2)$ \\
\hline $\begin{array}{l}\text { Nevirapine }+ \text { stavudine }+ \\
\text { lamivudine }\end{array}$ & $2(6.2)$ \\
\hline $\begin{array}{l}\text { Stavudine + lamivudine }+ \\
\text { efavirenz }\end{array}$ & $2(6.2)$ \\
\hline $\begin{array}{l}\text { Atazanavir }+ \text { ritonavir }+ \\
\text { tenofovir }\end{array}$ & $2(6.2)$ \\
\hline Zidovudine + lamivudine & $1(3.1)$ \\
\hline Stavudine + lamivudine & $1(3.1)$ \\
\hline $\begin{array}{l}\text { Atazanavir + ritonavir }+ \\
\text { tenofovir }+ \text { emtricitabine }\end{array}$ & $1(3.1)$ \\
\hline $\begin{array}{l}\text { Atazanavir }+ \text { tenofovir }+ \\
\text { emtricitabine }\end{array}$ & $1(3.1)$ \\
\hline $\begin{array}{l}\text { Indinavir + abacavir }+ \\
\text { tenofovir }\end{array}$ & $1(3.1)$ \\
\hline
\end{tabular}

good adherence to HAART. We found that short- and long-term adverse drug reactions to HAART such as red blood cell disorders, urinary system disorders, skin and appendages disorders, and gastrointestinal system disorders had contributed to non-adherence due to adverse side effects and affected quality of life during HIV treatment.

In our study, the occurrence of anemia and pancytopenia in HIV-infected patients due to the use of zidovudinecontaining HAART regimen impacts greatly with its associated symptoms of weakness, fatigue, nausea, and severe vomiting within 4-8 weeks of initiation of zidovudine-containing HAART regimen which leads to medication non-adherence in our patients. These data are in agreement with other studies ${ }^{[4,24]}$ demonstrating that either discontinuation of zidovudine to improve the hemoglobin level or a definite need of a change to some other HAART regimen is required for adherence.

In our study, the occurrence of moderate to severe renal dysfunction (12.6\%) was highly associated with the use of tenofovir-containing HAART regimen with the signs of proteinuria, fatigue, glucosuria, nausea, and weight loss within 5-12 months of initiation resulting for nonadherence. The renal function test and other laboratory values returned to normal within a few months after tenofovir discontinuation.

Our study highlights the use of tenofovir-containing HAART regimen which was associated with a small, 
Table 6: Causality assessment of adverse drug reactions

\begin{tabular}{|c|c|c|}
\hline \multicolumn{2}{|l|}{ Assessment of adverse drug reactions } & $\begin{array}{c}\begin{array}{c}\text { Number } \\
\text { of ADRs, } \\
n=\mathbf{3 2}\end{array} \\
(\%)\end{array}$ \\
\hline \multicolumn{3}{|l|}{ Causality of ADRs } \\
\hline \multicolumn{3}{|l|}{ WHO probability scale } \\
\hline Certain & & $6(18.8)$ \\
\hline Probable & & $16(50)$ \\
\hline Possible & & $10(31.2)$ \\
\hline \multicolumn{3}{|l|}{ Naranjo's scale } \\
\hline Definite & & $2(6.2)$ \\
\hline Probable & & $22(68.8)$ \\
\hline Possible & & $8(25)$ \\
\hline \multicolumn{3}{|l|}{ Severity (Hartwig et al.'s scale) } \\
\hline Mild & & $9(28.2)$ \\
\hline Moderate & & $23(71.8)$ \\
\hline Severe & & Nil \\
\hline \multicolumn{3}{|l|}{ Predictability } \\
\hline Predictable & & $28(87.5)$ \\
\hline Non predictable & & $4(12.5)$ \\
\hline \multicolumn{3}{|c|}{ Preventability (Modified Schumock and Thornton's scale) } \\
\hline Definitely preventable & & $9(28.1)$ \\
\hline Probably preventable & & $6(18.8)$ \\
\hline Not preventable & & $17(53.1)$ \\
\hline \multicolumn{3}{|l|}{ Management of ADRs } \\
\hline Drug withdrawn & & $20(62.5)$ \\
\hline Dose altered & & Nil \\
\hline No change & & $12(37.5)$ \\
\hline \multicolumn{3}{|l|}{ Treatment given } \\
\hline Specific & & $13(40.7)$ \\
\hline Symptomatic & & $11(34.3)$ \\
\hline No change in treatment & & $8(25)$ \\
\hline \multicolumn{3}{|l|}{ Outcome of management of ADRs } \\
\hline Recovered & & $25(78.1)$ \\
\hline Continuing & & $5(15.7)$ \\
\hline Unknown & & $2(6.2)$ \\
\hline \multicolumn{3}{|l|}{ Dechallenge } \\
\hline No dechallenge & & $11(34.3)$ \\
\hline Definite improvement & & $19(59.5)$ \\
\hline Unknown & & $2(6.2)$ \\
\hline \multicolumn{3}{|l|}{ Rechallenge } \\
\hline No rechallenge & & $30(93.8)$ \\
\hline No occurrence of symptoms & & $1(3.1)$ \\
\hline Unknown & & $1(3.1)$ \\
\hline \multicolumn{3}{|l|}{ Adverse drug reactions reported } \\
\hline Anemia & Zidovudine & $7(22)$ \\
\hline Pancytopenia & Zidovudine & $6(18.9)$ \\
\hline Leucopenia & Zidovudine & $1(3.1)$ \\
\hline Renal failure & Tenofovir & $4(12.6)$ \\
\hline SJS and TEN & Nevirapine & $3(9.3)$ \\
\hline Sensory neuropathy & Stavudine & $2(6.2)$ \\
\hline Hepatitis & Stavudine & $2(6.2)$ \\
\hline Hyperbilirubinemia & Atazanavir & $1(3.1)$ \\
\hline Maldistribution & Atazanavir & $1(3.1)$ \\
\hline Insomnia & Efavirenz & $1(3.1)$ \\
\hline Vomiting & Zidovudine & $1(3.1)$ \\
\hline IRIS & Efavirenz & $1(3.1)$ \\
\hline
\end{tabular}

Contd...
Table 6: Contd...

\begin{tabular}{lcc}
\hline Assessment of adverse drug reactions & $\begin{array}{c}\text { Number } \\
\text { of ADRs, } \\
n=32 \\
(\%)\end{array}$ \\
\hline Gastritis & $\begin{array}{c}\text { Efavirenz } \\
\text { Zidovudine }\end{array}$ & $1(3.1)$ \\
Fever & & \\
System organ class codes WHO-ART & $14(43.8)$ \\
Red blood cell disorders (1210) & $4(12.5)$ \\
Urinary system disorders (1300) & $3(9.3)$ \\
Skin and appendages disorders (0100) & $2(6.3)$ \\
Gastrointestinal system disorders (0600) & $2(6.3)$ \\
Central and peripheral nervous system & \\
disorders (0410) & $2(6.3)$ \\
Liver and biliary system disorders (0700) & $1(3.1)$ \\
White cell and RES disorders (1220) & $1(3.1)$ \\
Psychiatric disorders (0500) & $1(3.1)$ \\
Metabolic and nutritional disorders (0800) & $1(3.1)$ \\
Body as a whole - general disorders (1810) & $1(3.1)$ \\
Resistance mechanism disorders (1830) &
\end{tabular}

increased risk of grades 3-4 nephrotoxicity. In one of the four cases of tenofovir-induced renal failure, even after tenofovir discontinuation, the renal function test was abnormal and dialysis was performed. Our study findings are similar to a study ${ }^{[25]}$ where a similar type of nephrotoxicity with tenofovir usage was observed in HIVinfected patients.

In our study of HIV-infected patients (9.3\%), cutaneous drug eruptions, i.e., Steven-Johnson syndrome (SJS) and toxic epidermal necrolysis (TEN) were observed with protease inhibitors and most commonly nevirapine. This adverse drug reaction was presented in our patients with symptoms of painful swallowing, fever, stinging eyes, followed by the development of erythematous macules that progressed to flaccid blisters. SJS and TEN were managed by discontinuation of nevirapine and with supportive measures of intravenous fluid administration, antimicrobial therapy, electrolyte maintenance, and skin care. These observations are in agreement with the previously published study. ${ }^{[2]}$

In our study, we found that antiretroviral, toxic sensory neuropathy was observed in $6.2 \%$ of patients who were on nucleoside reverse transcriptase inhibitors (NRTIs), especially stavudine-containing HAART. Two patients who exhibited stavudine-induced sensory neuropathy were also suffering from depression due to chronic pain associated with neuropathic symptoms such as numbness, burning pain, and hyperesthesia resulting for nonadherence to antiretroviral therapy. Sensory neuropathy was managed by discontinuation of stavudine therapy, and the patient was 
also started on amitriptyline, $10 \mathrm{mg} \mathrm{HS}$, for relief of pain and depression management. Our findings are similar to those of other studies ${ }^{[27,28]}$ conducted elsewhere.

In our study, a patient with stavudine-containing HAART developed symptoms of liver disease during the first 2-3 months of HAART initiation, but the patient did not tell the physician about symptoms of adverse effects which resulted intentional non-adherence to HAART for a period of 10 days. Further, the patient was then presented to our HIV clinic with hepatomegaly with a fatty liver and lactic acidosis. Liver biopsy and an abnormal liver function test confirmed acute hepatitis. The offending drug stavudine was withdrawn and treatment was continued along with atazanavir + ritonavir + tenofovir combination. This finding is concurrent with another study. ${ }^{[29]}$

During this study, hyperbilirubinemia was observed in one patient who was on atazanavir-containing HAART regimen. A total of $3.1 \%$ of patients developed elevated indirect bilirubin levels, and after discontinuation of atazanavir, we found that indirect bilirubin levels and liver function tests were normal, similar to the finding of a study. ${ }^{[30]}$ In our study, fat maldistribution was reported in one patient within first 6 months of atazanavir-containing HAART regimen. This finding is concurrent with the study carried out by Paterson et al. ${ }^{[2]}$ Similar to other studies, ${ }^{[31-33]}$ central nervous system effects such as insomnia were reported in our patient during the first 3 days of efavirenz therapy. The patient who experienced insomnia due to efavirenz therapy was tolerable to the adverse effect, when the daily dose of efavirez was administered on an empty stomach, at bed-time.

In our study, gastrointestinal effects such as vomiting and anorexia were observed as a cause for non-adherence to antiretroviral therapy in one patient with asymptomatic HIV infection who was on zidovudine therapy during the first week. Gastrointestinal symptoms and HIV disease are more common in developing countries while opportunistic infection such as mycobacterium avium complex and cytomegalovirus are more in developed countries. However, these gastrointestinal symptoms were self-limiting. These findings are in agreement with another study. ${ }^{[34]}$

During the present study, one patient experienced immune reconstitution syndrome during initial treatment with combination antiretroviral therapy, including efavirenz and zidovudine. This patient developed an inflammatory response to opportunistic infections with Pneumocystis carinii pneumonia and cytomegalovirus infection. Our findings are similar to those of other studies ${ }^{[35,36]}$ conducted elsewhere.

\section{CONCLUSION}

Our study shows that the level of antiretroviral medication adherence in HIV patients was less than $80 \%$ in $46 \%$, $80 \%-95 \%$ in $28 \%$, and greater than $95 \%$ in $26 \%$ patients. Clinicians need to pay attention to make the HIV patient understand about the importance of good adherence to antiretroviral therapy. The need for awareness of possible side effects of antiretroviral therapy will be an essential method for the early prevention of ADRs.

\section{ACKNOWLEDGMENTS}

The authors wish to thank the staff of Medicine Department and administrative staff of Kasturba Medical College, Manipal University, Manipal, for their technical support and encouragement.

\section{REFERENCES}

1. Mannheimer S, Friedland G, Matts J, Child C, Chesney M. The consistency of adherence to antiretroviral therapy predicts biologic outcomes for human immunodeficiency virus-infected person in clinical trials. Clin Infect Dis 2002;34:1115-21.

2. Paterson DL, Swindells S, Mohr J, Brester M, Vergis EN, Squier C. Adherence to protease inhibitor therapy and outcomes in patients with HIV infection. Ann Intern Med 2000;133:21-30.

3. National AIDS Control Organization ministry of health and family welfare, government of India, (home page on the internet) (2009) Available at: URL: http://www.nacoonline.org/(accessed 31 August 2009).

4. Rajesh R, Vidyasagar S, Naren P, Manju V. Safety aspects of Antiretroviral therapy for management of HIV Infection. J basic clin Pharm 2010; 1:47- 53.

5. Chesney MA, Ickovics JR, Chambers DB. Self-reported adherence to antiretroviral medications among participants in HIV clinical trials: The ACTG Adherence Instruments. AIDS Care 2000;12:255-66.

6. A practical handbook on the pharmacovigilance of antiretroviral medicines. Publication of the World Health Organization, Geneva, Switzerland 2009:34-35.

7. Mombassa ART Project. Adherence to antiretroviral therapy in adults: A Guide for trainers. Kenya: Horizons population council; 2004.

8. Naranjo CA, Busto U, Sellers EM. A method for estimating the probability of adverse drug reactions Clin Pharmacol Ther 1981;30:239-45.

9. World Health Organization. Uppsala Monitoring Center.Safety monitoring of medicinal products, guidelines for setting 201 up and running phamacovigilance center, Geneva 1996. Available at: URL: http://www. who.int/en/ (accessed 25 January 2011).

10. Schumock GT, Thornton JP. Focusing on the preventability of adverse drug reactions Hosp Pharm 1992;27:538.

11. Hartwig SC, Siegel J, Schneider PJ. Preventability and severity assessment in reporting adverse drug reactions. Am J Hosp Pharm 1992; 49:2229-32.

12. International monitoring of adverse reactions to drugs, World Health Organization. Adverse Reaction Terminology. Publication of the Uppsala Monitoring Centre Uppsala, Sweden 2003.

13. Amberbir A, Woldemichael K, Getachew S, Girma B, Deribe K. Predictors of adherence to antiretroviral therapy among HIV-infected persons: A prospective study in Southwest Ethiopia. BMC Public Health 2008;8:265.

14. Gifford LA, Bormann JE, Shively MJ, Wright BC, Richman DD, Bozzette SA. Predictors of self-reported adherence and plasma HIV concentrations 
in patients on multidrug antiretroviral regimens. J Acquir Immune Defect Syndr 2000;23:386-95.

15. Burgos M, Revsin NS, Vilas A, Fontan L. Obstacles in treatment adherence: Patient reasons. [abstract 32400]. 12th World AIDS conference, Geneva, Switzerland: 1998.

16. Besch CL. Compliance in clinical trials. AIDS 1995;5:1-10.

17. Singh N, Berman SM, Swindells S. Adherence of human immunodeficiency virus- infected patients to antiretroviral therapy. Clin Infect Dis 1999; 29:824-30.

18. Amsten JH, Demas PA, Farzadegan H. Antiretroviral therapy adherence and viral suppression in HIV-infected drug users: Comparison of self-report and electronic monitoring.Clin Infect Dis 2001; 33:1417-23.

19. Bartlett JA. Addressing the challenges of adherence.J Acquir Immune Defic Syndr 2002;29:2-10.

20. Kumarasamy N, Safren SA, Raminani SR. Barriers and facilitators to antiretroviral medication adherence among patients with HIV in Chennai, India: A qualitative study. AIDS Patient Care STDS 2005; 19:526-37.

21. Fekete EM, Antoni MH, Duran R, Stoelb BL, Kumar M, Schneiderman N. Disclosing HIV serostatus to family members: Efeects on psychological and physiological health in minority women living with HIV. Int J BehavMed 2009; 16:367-76.

22. Vance D. The relationship between HIV disclosure and adjustment.Psychol Rep 2006;99:659-63.

23. Vyavaharkar M, Moneyham L, Corwin S, Tavakoli A, Saunders R, Annang L. HIV- disclosure, social support and depression among HIV-infection African American women living in the rural southeastern united states. AIDS Educ Prev 2011;23:78-90.

24. Modayil R, Anand H, Parthasarathi G, Ramesh M, Rajendra P, Vasudeva N,Vamadeva G. Adverse drug reactions to antiretroviral therapy (ART): An experience of spontaneous reporting and intensive monitoring from ART centre in India. Pharmacoepidemiol Drug Saf 2010;19:247-55.

25. Szczech LA. Renal dysfunction and tenofovir toxicity in HIV-infected patients. Top HIV Med 2008;16:122-5.

26. Ward H, Russo G, Shrum J. Cutaneous manifestation of antiretroviral therapy. J Am Acad Derm 2002;46:284-93.

27. Wulff E, Wang A, Simpson D. HIV- associated peripheral neuropathy: Epidemiology, pathophysiology and treatment. Drugs 2000; 59:1251-60.
28. Sadler M, Nelson M. Peripheral neuropathy in HIV. Int J STD AIDS 1997;8:16-21.

29. Sulkowski M, Mehta S, Thomas D, Moore R. Hepatotoxicity associated with NNRTI use: Role of drugs and chronic hepatitis. 8th Conference on Retroviruses and opportunistic Infections. Feb 4-8; Chicago: 2001. Abstract. p. 618.

30. Sanne I, Piliero P, Squires K, Thury A, Schnittman S. Group A-CT, Results of a phase 2 clinical trial at 48 weeks (AI424-007): A dose-ranging, safety and efficacy comparative trial of atazanavir at three doses in combination with didanosine and stavudine in antiretroviral-native subjects. J Acquir Immune Defic Syndr 2003;32:18-29.

31. Staszewski S, Morales J, Tashima KT. A phase III, multicenter, randomized study comparing the antiretroviral activity and tolerability of evavirenz plus indinavir, versus efavirenz plus zidovudine and lamivudine, versus indinavir plus zidovudine and lamivudine in treatment naïve HIV-1 infected patients (study 006). N Engl J Med 1999;341:1865-73.

32. AHFS drug information. Am J Health Syst Pharm 2010.717-726.

33. Sustivatm (efavirenz) capsules, Du Pont Pharmaceuticals Company. Wilmington, DE, US: Prescribing Information; 2000.

34. Luber A, Garg V, Gharakhanian S. Vertex HIV program team, survey of medication used by HIV-infected patients that affect gastrointestinal acidity and potential for negative drug interactions with HAART, program and abstract of 7 th International congress on drug therapy in HIV infection, November 14-18. Glasgow, UK: 2004. Poster.p. 206.

35. Tashima K, Staszewski S, Nelson M. Efavirenz (Sustiva) - based HAART: 168 weeks of follow-up (3-4 yrs) of original 006 EFV pivotal study, XV International AIDS Conference. Bangkok: 11-16 Jul 2004. Abstract TuPeB4547.

36. Murdoch DM, Venter WD, Feldman C, Vanrie A. Incidence and risk factors for the immune reconstitution inflammatory syndrome in HIV patients in South Africa: A prospective study. AIDS 2008; 22:601-10.

How to cite this article: Rajesh R, Sudha V, Varma DM, Sonika S. Association between medication adherence outcomes and adverse drug reactions to highly active antiretroviral therapy in Indian human immunodeficiency virus-positive patients. J Young Pharmacists 2012;4:250-60.

Source of Support: Nil, Conflict of Interest: None declared.

\section{Staying in touch with the journal}

1) Table of Contents (TOC) email alert Receive an email alert containing the TOC when a new complete issue of the journal is made available online. To register for TOC alerts go to www.jyoungpharm.in/signup.asp.

\section{2) RSS feeds}

Really Simple Syndication (RSS) helps you to get alerts on new publication right on your desktop without going to the journal's website. You need a software (e.g. RSSReader, Feed Demon, FeedReader, My Yahoo!, NewsGator and NewzCrawler) to get advantage of this tool. RSS feeds can also be read through FireFox or Microsoft Outlook 2007. Once any of these small (and mostly free) software is installed, add www.jyoungpharm.in/rssfeed.asp as one of the feeds. 